\title{
Fast determination of Sudan dyes in chilli tomato sauces using partial filling micellar electrokinetic chromatography
}

\author{
Tatiana S. Fukuji ${ }^{1,2}$, María Castro-Puyana ${ }^{1}$, Marina F. M. Tavares ${ }^{2}$, \\ Alejandro Cifuentes ${ }^{1, *}$ \\ ${ }^{1}$ Laboratory of Foodomics, CIAL, CSIC, Nicolas Cabrera 9, Campus Cantoblanco, \\ 28049 Madrid, Spain \\ ${ }^{2}$ Institute of Chemistry, University of Sao Paulo, Av. Prof. Lineu Prestes 748, 05508 \\ Sao Paulo, Brazil
}

Correspondence: Prof. Alejandro Cifuentes, Laboratory of Foodomics, CIAL, CSIC, Nicolas Cabrera 9, Campus Cantoblanco, 28049 Madrid. Spain

Email: a.cifuentes@csic.es

Fax: $+34-910017905$ 


\section{ABSTRACT}

2

3 A new method based on partial filling micellar electrokinetic chromatography (MEKC)

4 for the quantitative determination of Sudan dyes (I, II, III and IV) in chilli sauces is

5 presented. The separation is achieved filling $25 \%$ of the capillary with a MEKC buffer

6 composed of $40 \mathrm{mM} \mathrm{NH}_{4} \mathrm{HCO}_{3}, 25 \mathrm{mM} \mathrm{SDS}$ and $32.5 \%(\mathrm{v} / \mathrm{v})$ acetonitrile (ACN). The

7 rest of the capillary is filled using a capillary zone electrophoresis (CZE) buffer

8 composed of $40 \mathrm{mM} \mathrm{NH} \mathrm{HCO}_{3}$ and $32.5 \%$ (v/v) ACN. Under optimized conditions,

9 the azo-dyes are baseline separated in less than 8 min with limits of detection (LODs)

10 ranging from 0.57 to $0.71 \mu \mathrm{g} \mathrm{mL} L^{-1}(\mathrm{~S} / \mathrm{N}>3)$. Using an internal standard the

11 repeatability of the quantitative determination is improved almost four times. The

12 applicability of the method for rapid screening and determination of Sudan dyes is

13 corroborated by analyzing spiked chilli sauce samples with recoveries from 85 to $99 \%$.

14 The reported conditions are demonstrated to be compatible with mass spectrometry

15 (MS) detection.

16

17 Keywords: dyes, capillary electrophoresis, MEKC, tomato chilli sauce, food analysis. 
Sudan dyes are a family of lipophilic synthetic organic colorants, characterized by a chromophoric azo-group, extensively used in industrial and scientific applications but banned as food colorants $(1,2)$. Sudan I, II, III, and IV (see Figure 1) are non-ionic fat-soluble dyes used as additives in gasoline, grease, oils and plastics. These dyes are

24 classified by the International Agency for Research on Cancer (IARC) as category 3 carcinogens because they can induce some forms of liver and bladder cancer in animals (3). Moreover, these dyes can generate metabolites that are converted to active mutagens and carcinogens in humans (4). For instance, the azo group of these dyes can be reduced to aromatic amines that are confirmed or suspected carcinogenic compounds (5). Sudan dyes have been illegally added to foodstuffs to enhance the red-orange color of products and easily used because of their low cost and wide availability. Due to the continuing illicit use of Sudan dyes as food colorants including some recent episodes of contamination of hot chilli and derived products from India and marketed in the European Union (6), their determination in different food matrices, especially in

34 different chilli and tomato sauces and related products, has received increasing attention during the last years $(7,8)$. As a result, development of new and fast analytical methods is still required for the identification and quantification of such compounds in 37 foodstuffs.

A wide variety of analytical methodologies have been developed for the determination of Sudan dyes in foodstuffs as recently reviewed by Rebane et al. (7).

40 Among the different methodologies developed so far, the most popular are based on the use of high performance liquid chromatography (HPLC) with optical (9-14), or mass spectrometric detection $(6,15-21)$. Although a great amount of information can be 
43 obtained by these methodologies, they are time consuming, need large sample volumes,

44 generate large amounts of waste, or require bulky and expensive instrumentation. Capillary electrophoresis (CE) has been shown as a powerful analytical technique to analyze additives and organic contaminants in foods (22-24) including the separation of Sudan dyes by MEKC with UV detection (25) and pressurized capillary electrochromatography (CEC) with amperometric detection (26). The work described by Liu et al. (26) showed the baseline separation of Sudan I, II, III, and IV in hot chilli powder within $7 \mathrm{~min}$ using capillaries of $20 \mathrm{~cm}$ packed with $1.5 \mu \mathrm{m}$ octadecyl silica particles (ODS) with LODs from 0.8 to $1.2 \mu \mathrm{M}$. On the other hand, Mejia et al. (25) carried out the determination of Sudan I, II, III, and IV in chilli power using a MEKC method based on the use of borate buffer containing SDS and acetonitrile (ACN). The

54 Sudan dyes were separated in $20 \mathrm{~min}$ with LODs from 0.1 to $0.6 \mu \mathrm{g} \mathrm{mL}^{-1}$.

CE provides high-speed, high-throughput, low waste generation, highly efficient and reliable separations, and it offers a simple way to handle very small samples (nL). However, it typically suffers from low concentration sensitivity as a consequence of the limited sample volume and short path length for absorbance based detection. This paper describes the development and application of the first capillary electrophoresis method compatible with mass spectrometry (MS) for the simultaneous determination of Sudan dyes (I, II, III, and IV). The described method is based on the use of a straightforward sample preparation step followed by partial filling micellar electrokinteic chromatography allowing a fast and inexpensive screening of the four Sudan dyes in

64 food samples. Moreover, the reported conditions are demonstrated to be compatible with mass spectrometry (MS) detection. 
70

\section{Reagents and solutions}

All reagents were of analytical grade, solvents were of chromatographic purity and water was purified using a Milli-Q system (Millipore, Bedford, MA, U.S.A.). ACN, acetone, dichloromethane and methanol were of chromatographic purity and obtained from Lab-Scan (Gliwice, Poland). Sodium hydroxide was obtained from Panreac (Barcelona, Spain).

Electrolyte solutions were prepared daily to the desired concentration from stock solutions of $100 \mathrm{mM}$ of ammonium hydrogen carbonate $\left(\mathrm{NH}_{4} \mathrm{HCO}_{3}\right.$, Fluka, Buchs, Switzerland) and sodium dodecyl sulfate (SDS) (Sigma Aldrich, St Louis, MO, U.S.A.). Sudan I (1-(phenylazo)-2-naphthalenol) and Sudan II (1-[(2,4dimethylphenyl)azo]-2-naphthalenol) were obtained from Sigma Aldrich (St Louis, MO, U.S.A.). Sudan III (1-(4-phenylazophenylazo)-2-naphthalenol) and Sudan IV (otolylazo-otolylazo-betanaphthalenol) were obtained from Fluka (Buchs, Switzerland). The molecular structures of these dyes are shown in Figure 1. Stock solutions of Sudan I and II were prepared at $1 \mathrm{mg} \mathrm{mL}^{-1}$ concentration and Sudan III and IV at $0.25 \mathrm{mg} \mathrm{mL}^{-1}$ all in acetone and stored at $4{ }^{\circ} \mathrm{C}$ until use. Working solutions containing 10 or $20 \mu \mathrm{g}$ $\mathrm{mL}^{-1}$ of each dye were prepared diluting the stock solutions as described below. Likewise, for the calibration curves, standard solutions from 2.5 to $20 \mu \mathrm{g} \mathrm{mL}^{-1}$ of each dye were prepared by appropriate dilution of the stocks. Namely, the Sudan I-IV standard solution in acetone was first diluted in a MEKC buffer (50:50 v/v) composed of $30 \mathrm{mM} \mathrm{NH} \mathrm{HCO}_{3}, 25 \mathrm{mM}$ SDS and $30 \% \mathrm{ACN}$. Since it was observed that an increase of the concentration of ammonium bicarbonate and SDS improved the peak shape, the concentration of the MEKC solution used to dilute the Sudan I-IV standard 

acetone mixture $(50: 50 \mathrm{v} / \mathrm{v})$ was raised to $60 \mathrm{mM} \mathrm{NH} \mathrm{NHCO}_{3}, 50 \mathrm{mM}$ SDS and $30 \%$ ACN.

Flumequine (Riedel-de Haën, Seelze, Germany) was used as internal standard. It was added to all samples at a concentration of $10 \mu \mathrm{g} \mathrm{mL} \mathrm{m}^{-1}$ prepared diluting a stock solution of $1 \mathrm{mg} \mathrm{mL}^{-1}$ in acetone.

\section{Sample preparation}

Samples of chilli tomato sauce were acquired from local markets. The procedure of extraction used a mixture of acetone, dichloromethane and methanol $(3: 2: 1, \mathrm{v} / \mathrm{v} / \mathrm{v})$ modifying the method proposed by Ertaş et al. (11). Namely, $1.0 \mathrm{~g}$ of sample was weighed into a sample tube and diluted with $10 \mathrm{~mL}$ of the above-mentioned three solvents mixture. Then, the sample was vortexed for $2 \mathrm{~min}$, sonicated for $5 \mathrm{~min}$ and centrifuged for $5 \mathrm{~min}$ at $10000 \mathrm{rpm}$ to precipitate the solids. The supernatant was collected and evaporated in a rotary evaporator. The dry residue was suspended in $1 \mathrm{~mL}$ of acetone containing the internal standard. This solution was diluted (50:50 v/v) in 60 mM NH $\mathrm{NHCO}_{3}$ with $50 \mathrm{mM}$ SDS and $30 \%$ ACN. Spiked samples were prepared by adding the Sudan dyes into the real samples before extraction. Recoveries were calculated using the average peak relative areas of the spiked samples to the internal standard and the obtained calibration curves.

\section{Instrumentation}

MEKC-UV: Partial filling MEKC experiments were conducted in a capillary electrophoresis system (model P/ACE MDQ, Beckman Instruments, Fullerton, CA, U.S.A.) equipped with a direct UV detector set at $214 \mathrm{~nm}$. Acquisition and data treatment was done using System Gold® Software supplied by Beckman. Uncoated 
118 fused-silica capillaries (Composite Metal Services, Worcester, UK) with $60.0 \mathrm{~cm}$ total 119 length (50.0 cm effective length) $\times 50 \mu \mathrm{m}$ i.d. were used. New capillaries were 120 preconditioned by flushing the capillary (at $20 \mathrm{psi}$ ) with $0.1 \mathrm{M} \mathrm{NaOH}$ for $30 \mathrm{~min}$ 121 followed by deionized water for $15 \mathrm{~min}$. At the beginning of each day, the capillary was 122 conditioned by flushing $0.1 \mathrm{M} \mathrm{NaOH}$ for $10 \mathrm{~min}$, deionized water for $10 \mathrm{~min}$ and 123 electrolyte solution for $5 \mathrm{~min}$, whereas at the end of the day, the capillary was rinsed 124 with $0.1 \mathrm{M} \mathrm{NaOH}$ and deionized water for 5 min each. Between runs, the capillary was 125 conditioned with CZE buffer (containing the concentration of $\mathrm{NH}_{4} \mathrm{HCO}_{3}$ and $\mathrm{ACN}$ 126 indicated in each case) for $5 \mathrm{~min}$. Then the MEKC buffer (containing the concentration 127 of $\mathrm{NH}_{4} \mathrm{HCO}_{3}$, SDS and $\mathrm{ACN}$ indicated in each experiment) was pushed in the capillary 128 filling the percentage indicated in each case. The total length of the MEKC plug was varied from $20 \%(12 \mathrm{~cm})$ to $100 \%(60 \mathrm{~cm})$ of the total capillary length (calculated with

130 CE Expert 1.0 Program, Beckman Instruments). The samples were injected into the 131 capillary using nitrogen at $0.5 \mathrm{psi}$ for $5 \mathrm{~s}$. Finally, the separation was performed placing 132 the CZE buffer solution at the inlet vial. The operating voltage was $+30 \mathrm{kV}$ and the 133 temperature was $25^{\circ} \mathrm{C}$.

134 MEKC-MS: MEKC-MS studies were carried out using a CE system (P/ACE 1355010 Beckman Instruments, Fullerton, CA, USA) controlled by a PC running System 136 GOLD software from Beckman. The MS employed was an ion trap (IT) mass 137 spectrometer (Esquire 2000, Bruker Daltonics, Bremen, Germany) equipped with an 138 orthogonal electrospray interface (model G1607A from Agilent Technologies, Palo 139 Alto, CA, USA). This instrument was controlled by a PC running the Esquire NT 140 software from Bruker Daltonics. Electrical contact at the electrospray needle tip was 141 established using isopropanol:water $(50: 50, \mathrm{v} / \mathrm{v})$ with $0.1 \%$ formic acid as sheath liquid 142 at a flow rate of $4 \mu \mathrm{L} / \mathrm{min}$ by a Cole Palmer syringe pump (Vernon Hills, IL, USA). 
143 Nebulizer pressure, drying gas flow and drying temperature were $4.0 \mathrm{psi}, 4.0 \mathrm{~L} / \mathrm{min}$, and

$144200{ }^{\circ} \mathrm{C}$ respectively, and the electrospray operated in the positive ion mode $(4.5 \mathrm{kV})$.

145 The $\mathrm{m} / \mathrm{z}$ range scanned by the mass spectrometer was from $100-400 \mathrm{~m} / \mathrm{z}$.

146 Separations were performed using uncoated fused-silica capillaries with a total

147 length of $80 \mathrm{~cm} \times 50 \mu \mathrm{m}$ i.d. The total length of the MEKC plug was $25 \%$ of the 148 capillary length $(20 \mathrm{~cm})$. Sample injections were made at 0.5 psi for $6 \mathrm{~s}$ and the 149 separation was achieved applying a voltage of $25 \mathrm{kV}$.

\section{$151 \quad$ RESULTS AND DISCUSSION}

\section{Method development}

Sudan dyes (see Figure 1) are lypophilic compounds and weak acids with pKa

154 values around 11.65. Because of their neutral nature the separation of these dyes was studied by MEKC trying to develop a partial filling method compatible in the future

156 with electrospray-MS detection. Different background electrolyte (BGE) compositions

157 using volatile buffers (ammonium acetate and ammonium bicarbonate) plus SDS were 158 investigated to separate the compounds by partial filling MEKC. Different organic 159 solvents were also added to the BGE in order to increase the solubility of these 160 hydrophobic analytes. First, Sudan I-IV solubilities were studied in mixtures of water 161 and organic solvents, observing that the dyes were more soluble in ACN, acetone and 162 isopropanol. In good agreement with Mejia et al. (25), ACN gave better separation 163 when it was used as organic modifier in the MEKC buffer. The best separation 164 conditions were obtained using $\mathrm{NH}_{4} \mathrm{HCO}_{3}$, SDS and ACN. Thus, the effect of different concentrations of $\mathrm{NH}_{4} \mathrm{HCO}_{3}$, SDS and percentage of ACN on the MEKC separation of

166 the four investigated dyes was explored. As can be observed in Figure 2A, the four

167 Sudan dyes were not separated when a concentration of $15 \mathrm{mM}$ SDS was used, whereas 
168 broader peaks were observed when $50 \mathrm{mM}$ SDS was employed, obtaining a good

169 compromise between separation and peak broadening using $25 \mathrm{mM}$ of SDS. Next, using

170 a concentration of $25 \mathrm{mM}$ SDS the effect of the concentration of $\mathrm{NH}_{4} \mathrm{HCO}_{3}$ was

171 investigated. As shown the Figure $2 \mathrm{~B}$, using a high concentration $\left(40 \mathrm{mM} \mathrm{NH} \mathrm{HCO}_{3}\right)$

172 broader peaks and longer migration times were obtained, while the use of a low

173 concentration $\left(20 \mathrm{mM} \mathrm{NH} \mathrm{NHCO}_{3}\right)$ decreased the resolution between peaks. Thus, a

174 concentration of $30 \mathrm{mM} \mathrm{NH} \mathrm{HCO}_{3}$ containing $25 \mathrm{mM}$ of SDS and $30 \% \mathrm{ACN}$ was

175 chosen as the optimum conditions for the separation of the four Sudan dyes, observing

176 that an increase of the percentage of ACN to either 35 or $40 \%$ generated a decrease of

177 resolution (data not shown). Although the selected BGE composed of $30 \mathrm{mM}$

$178 \mathrm{NH}_{4} \mathrm{HCO}_{3}, 25 \mathrm{mM}$ of SDS and $30 \% \mathrm{ACN}$ enabled the separation of the four dyes, it

179 could not be used in combination with MS detection because of the contamination of

180 the ion source induced by the presence of SDS in the BGE, which causes low ionization

181 efficiencies and loss of detection sensitivity (27-29). To avoid that SDS reaches the MS

182 detector, the use of partial filling was investigated to make compatible the MEKC

183 conditions with electrospray-MS detection (29). Then, the MEKC buffer composed of

$18430 \mathrm{mM} \mathrm{NH}_{4} \mathrm{HCO}_{3}, 25 \mathrm{mM}$ SDS with $30 \% \mathrm{ACN}$ was used to fill 20, 25, 50, 75 or 100

$185 \%$ of the capillary. The rest of the capillary was filled with a CZE buffer composed of

$18630 \mathrm{mM}$ of $\mathrm{NH}_{4} \mathrm{HCO}_{3}$ and $30 \% \mathrm{ACN}$. Filling the $20 \%$ of the capillary with MEKC

187 buffer led to the lost of the baseline resolution (data not shown). The best conditions in

188 terms of analysis speed and peak shape were obtained filling $25 \%$ of the capillary

189 length with the MEKC buffer providing analysis time shorter than 7 min as can be 190 observed in Figure 3.

191

192 Method repeatability and quantitative analysis 
194 repeatability. As can be observed in Table 1 the relative standard deviation $\left(\% \mathrm{RSD}_{\mathrm{n}=10}\right)$

195 varied from 1.3 to $3.1 \%$ for the analysis time and from 12.5 to $25.5 \%$ for the relative

196 peak area. These latter values are unacceptable for quantitative analysis. For this reason,

197 flumequine was selected among different compounds as internal standard (IS). This

198 compound fulfills the requirements of no interfering with the analytes migration time

199 and it has similar solubility, electrophoretic mobility and extinction coefficient that the

200 studied compounds. Thus, the values of $\%$ RSD were improved more than 3 times for

201 Sudan I, II and III by using a relative peak area which was calculated dividing the

202 analyte corrected peak are by the I.S corrected peak area (see Table 1). However, the \%

203 RSD value obtained for Sudan IV was still too high (25.4\%). This fact is probably due

204 to the low solubility of this analyte that causes poor peak shape (see Sudan IV peak in

205 Figure 4A). In order to improve this result an additional study of the analytes solubility

206 was carried out. The solubility of the dyes could be improved increasing the percentage

207 of ACN from $30 \%$ to $35 \%$ as could be deduced from their peak shapes. However,

208 using $35 \%$ ACN, the separation was lost. Therefore, concentration of $\mathrm{NH}_{4} \mathrm{HCO}_{3}$ and

209 SDS were again varied to improve both solubility and resolution. Increasing the SDS

210 concentration and using $40 \mathrm{mM}$ of $\mathrm{NH}_{4} \mathrm{HCO}_{3}$ and $35 \%$ of $\mathrm{ACN}$ better peak shapes and

211 a slightly improvement of the resolution was observed. However, complete baseline

212 separation of the four analytes could not be obtained. A more subtle optimization of the

213 separation conditions was then carried out, concluding that a partial filling of $25 \%$ with

214 a MEKC buffer composed of $40 \mathrm{mM} \mathrm{NH} \mathrm{HCO}_{3}, 25 \mathrm{mM}$ SDS and $32.5 \%$ ACN

215 provided baseline separation of the four compounds with good peak shapes for all the

216 Sudan dyes as can be deduced from Figure 4B. Under these new conditions, both

217 repeatability and sensitivity of the method were improved as can be deduced comparing 
218 the results from Table 1 and 2. The LODs for Sudan I-IV were improved from 1.28-

$2193.07 \mu \mathrm{g} \mathrm{mL}^{-1}$ to $0.57-0.71 \mu \mathrm{g} \mathrm{mL}^{-1}$. In addition, the relative peak area repeatability for

220 Sudan IV improved from $25.4 \%$ to $8.8 \%$. Using these conditions, the inter-day

221 repeatability and the linearity of the method were studied. The results obtained for the

222 inter-day repeatability (see Table 2 ) provided \% RSD values lower than $10 \%$ in all

223 cases. With regards to the linearity, it was determined by plotting the peak areas as a

224 function of the Sudan I-IV concentration in $\mu \mathrm{g} \mathrm{mL}{ }^{-1}$. The intercept, slope, correlation

225 coefficient $\left(\mathrm{R}^{2}\right)$, and the regression standard error for each of the Sudan dyes are shown

226 in Table 3. For the linear range studied from 2.5 to $20 \mu \mathrm{g} \mathrm{mL}^{-1}$ (namely, 2.5, 5, 7.5, 10,

$22712.5,15$, and $20 \mu \mathrm{g} \mathrm{mL}^{-1}$ ), values of $\mathrm{R}^{2}$ higher than 0.99 were obtained in all cases,

228 corroborating the good possibilities of this method for the quantitative analysis of Sudan

229 dyes in food additives.

230 Application to real samples

231 The proposed method was applied to the identification and determination of

232 Sudan dyes in three different samples of chilli tomato sauces. No presence of Sudan dye

233 was detected in any of the studied samples. Thus, in order to demonstrate the

234 applicability and accuracy of this new method, the samples were spiked with known

235 amount of Sudan dyes.

236 Accuracy of the method was evaluated as the recovery obtained by each Sudan

237 dyes when spiking the samples of chilli tomato sauces with $2.5 \mu \mathrm{g} \mathrm{mL} \mathrm{L}^{-1}$ of Sudan I and

238 II and $5.0 \mu \mathrm{g} \mathrm{mL}^{-1}$ of Sudan III and IV. Table 4 shows that the recovery values obtained

239 for Sudan I and II were from 92.1 to $99.0 \%$ while the values obtained for Sudan III and

240 IV were lower (from 85.2 to $92.1 \%$ ). These data are in agreement with the literature

241 where the recoveries values depend on the solvent utilized for the extraction and the

242 matrix of the samples, being generally lower for Sudan IV (7). 
Figure 5 shows the electropherograms obtained under the optimized conditions

244 for the separation of Sudan I, II, III and IV from a spiked chilli tomato sauce, namely,

245 the chilli tomato sauce was spiked with $2.5 \mu \mathrm{g} \mathrm{mL}^{-1}$ of Sudan I and II and $5 \mu \mathrm{g} \mathrm{mL} L^{-1}$ of

246 Sudan III and IV. LOD slightly higher than those obtained for the standard samples

247 were obtained for chilli tomato sauce. Namely, the LOD was $0.68,0.63,0.94$ and 1.25

$248 \mu \mathrm{g} \mathrm{mL}^{-1}$ for Sudan I, II, III, and IV, respectively. This fact can be explained by both the

249 recoveries mentioned above (from 85 to 99\%) and the presence of interferences from

250 the matrix that can negatively affect the separation and detection of the dyes. This figure

251 demonstrates the selectivity of the method developed in this work since it provides an

252 adequate separation between the Sudan dyes studied and the rest of constituents from

253 the complex matrix of the chilli tomato sauce.

\section{Preliminary MEKC-MS results.}

The compatibility of the developed MEKC method with MS detection was studied for the simultaneous determination of Sudan dyes. Due to instrumental constrains the coupling MEKC-MS needs longer capillary, thus, the injection time of samples and the plug were adapted to the dimension of the capillary in order to carry out 260 the analysis in comparable condition with MEKC-UV. Besides, several analytical 261 parameters, such as ESI voltage, nature of sheath liquid, temperature and flow of dry 262 gas were optimized in order to obtain the higher intensity in the MS signal by flushing 263 the standards by low pressure (0.5 psi) towards the MS instrument. The highest intensity 264 of the MS signals was obtained using the ESI source in positive mode $(4.5 \mathrm{kV})$, isopropanol:water $(50: 50 \mathrm{v} / \mathrm{v})$ with $0.1 \%$ formic acid as sheath liquid and a temperature of dry gas of $200{ }^{\circ} \mathrm{C}$ flowing at $4 \mathrm{~L} / \mathrm{min}$. Figure 6 depicts the partial filling MEKC-MS 
dyes. As can be observed in this figure, the $[\mathrm{M}-\mathrm{H}]^{+}$obtained for each dye was: 249.2,

$269277.1,353.2$ and $381.2 \mathrm{~m} / \mathrm{z}$ for Sudan I, II, III, and IV, respectively (values that are in

270 good agreement with the expected molecular weight for these compounds: 248.3, 276.3,

271352.4 and $380.4 \mathrm{~g} \mathrm{~mol}^{-1}$, respectively). Under these conditions, the LODs obtained were

272 ranging from 0.52 to $1.67 \mu \mathrm{g} / \mathrm{mL}$ for the four dyes. These LODs are similar to those

273 obtained by MEKC-UV, although they could be improved by using MS/MS in multiple

274 reaction monitoring (MRM) mode. This possibility is currently being under study at our

275 laboratory.

276

277

In summary, a new method for the determination of Sudan dyes by partial filling

278 micellar electrokinetic chromatography was developed. After a fine optimization of the

279 analytical conditions (BGE composition and ionic strenght, surfactant concentration,

280 type and percentage of organic modifier, and percentage of capillary filled with the MEKC solution) a fast method was achieved that allows the simultaneous determination of Sudan dyes (I, II, III, and IV) in less than 8 min with minimum instrumentation needs and cost. The LODs provided by this method were ranging from 570 to $710 \mathrm{ng} \mathrm{mL}^{-1}$.

284 Although samples containing Sudan dyes were not found, the method was successfully applied for the analysis of Sudan dyes (I, II, III and IV) in spiked chilli tomato sauces samples with good recoveries, showing the potential of the method for quality control of food samples. Moreover, the partial filling MEKC method is also demonstrated to be compatible with MS detection.

\section{ACKNOWLEDGEMENTS}

291 This work was supported by AGL2008-05108-C03-01 (Ministerio de Ciencia e 292 Innovación, MICCIN, Spain), and CSD2007-00063 FUN-C-FOOD (Programa 
293 CONSOLIDER, Ministerio de Educacion y Ciencia, Spain). M.C.P. thanks MICCIN for

294 her "Juan de la Cierva" contract (JCI-2009-05297). T.S.F. thanks Fapesp of Brazil 295 (Fundação de Amparo à Pesquisa do Estado de São Paulo, 07/53470-3) for her 296 fellowship.

297 


\section{REFERENCES}

299 1. Comission Decision of 20 June 2003 on emergency measures regarding hot chilli and

300 hot chilli products (notified under document number C(2003) 1970) 2003/460/EC. O.J.

301 2003, L154, 114-113.

302 2. Comission Decision of 21 January 2004 on emergency measures regarding hot chilli

303 and hot chilli product (notified under document number C (2004) 68) 2004/92/EC, O. J.

304 2004, L 27, 52-54.

305 3. International Agency for Research on Cancer, Some aromatic azo compounds. IARC

306 Monogr. eval. carcinog. risks hum. suppl., 1975, 8, 225-241.

307 4. Li, L.; Gao, H. W.; Ren, J. R.; Chen, L.; Li, Y. C.; Zhao, J. F.; Zhao, H. P.; Yuan, Y.

308 Binding of Sudan II and IV to lecithin liposomes and E-coli membranes: insights into

309 the toxicity of hydrophobic azo dyes. BMC Struct. Biol. 2007, 7, 16-17.

310 5. Ahlstrom, L. H.; Eskilsson, C. S.; Bjorklund, E. Determination of banned azo dyes in

311 consumer goods. TrAC-Trends Anal. Chem. 2005, 24 (1), 49-56.

312 6. Calbiani, F.; Careri, M.; Elviri, L.; Mangia, A.; Pistara, L.; Zagnoni, I. Development

313 and in-house validation of a liquid chromatography-electrospray-tandem mass

314 spectrometry method for the simultaneous determination of Sudan I, Sudan II, Sudan III

315 and Sudan IV in hot chilli products. J. Chromatogr A 2004, 1042 (1-2), 123-130.

316 7. Rebane, R.; Leito, I.; Yurchenko, S.; Herodes, K. A review of analytical techniques

317 for determination of Sudan I-IV dyes in food matrixes. J. Chromatogr. A 2010, 1217

318 (17), 2747-2757.

319 8. Kucharska, M.; Grabka, J. A review of chromatographic methods for determination 320 of synthetic food dyes. Talanta 2010, 80 (3), 1045-1051.

321 9. Cornet, V.; Govaert, Y.; Moens, G.; Van Loco, J.; Degroodt, J. M. Development of a

322 fast analytical method for the determination of sudan dyes in chili- and curry-containing 
323 foodstuffs by high-performance liquid chromatography-photodiode array detection. $J$.

324 Agric. Food Chem. 2006, 54 (3), 639-644.

325 10. Uematsu, Y.; Ogimoto, M.; Kabashima, J.; Suzuki, K.; Ito, K. Fast cleanup method 326 for the analysis of sudan I-IV and para red in various foods and paprika color 327 (oleoresin) by high-performance liquid chromatography/diode array detection: Focus on 328 removal of fat and oil as fatty acid methyl esters prepared by transesterification of 329 acylglycerols. J. AOAC Int. 2007, 90 (2), 437-445.

330 11. Ertas, E.; Ozer, H.; Alasalvar, C. A rapid HPLC method for determination of Sudan 331 dyes and Para Red in red chilli pepper. Food Chem. 2007, 105 (2), 756-760.

332 12. Di Anibal, C. V.; Odena, M.; Ruisanchez, I.; Callao, M. P. Determining the 333 adulteration of spices with Sudan I-II-II-IV dyes by UV-visible spectroscopy and 334 multivariate classification techniques. Talanta 2009, 79 (3), 887-892.

335 13. Avila, M.; Zougagh, M.; Escarpa, A.; Rios, A. Determination of sudan dyes in food 336 samples using supercritical fluid extraction-capillary liquid chromatography. $J$. 337 Supercrit. Fluids 2011, 55 (3), 977-982.

338 14. He, L. M.; Su, Y. J.; Fang, B. H.; Shen, X. G.; Zeng, Z. L.; Liu, Y. H. 339 Determination of Sudan dye residues in eggs by liquid chromatography and gas 340 chromatography-mass spectrometry. Anal. Chim. Acta 2007, 594 (1), 139-146.

341 15. Yu, C. H.; Liu, Q.; Lan, L. D.; Hu, B. Comparison of dual solvent-stir bars 342 microextraction and U-shaped hollow fiber-liquid phase microextraction for the analysis 343 of Sudan dyes in food samples by high-performance liquid chromatography344 ultraviolet/mass spectrometry. J. Chromatogr. A 2008, 1188 (2), 124-131.

345 16. Molder, K.; Kunnapas, A.; Herodes, K.; Leito, I. "Fast peaks" in chromatograms of 346 Sudan dyes. J. Chromatogr. A 2007, 1160 (1-2), 227-234. 
347 17. Sun, H. W.; Wang, F. C.; Ai, L. F. Determination of banned 10 azo-dyes in hot chili

348 products by gel permeation chromatograph-liquid chromatography-electrospray

349 ionization-tandem mass spectrometry. J. Chromatogr. A 2007, 1164 (1-2), 120-128.

350 18. Botek, P.; Poustka, J.; Hajslova, J. Determination of banned dyes in spices by liquid

351 chromatography-mass spectrometry. Czech J. Food Sci. 2007, 25 (1), 17-24.

352 19. Noguerol-Cal, R.; Lopez-Vilarino, J. M.; Fernandez-Martinez, G.; Barral-Losada,

353 L.; Gonzalez-Rodriguez, M. V. High-performance liquid chromatography analysis of 354 ten dyes for control of safety of commercial articles. J. Chromatogr. A 2008, 1179 (2), $355 \quad 152-160$.

356 20. Pardo, O.; Yusa, V.; Leon, N.; Pastor, A. Development of a method for the analysis 357 of seven banned azo-dyes in chilli and hot chilli food samples by pressurised liquid 358 extraction and liquid chromatography with electrospray ionization-tandem mass 359 spectrometry. Talanta 2009, 78 (1), 178-186.

360 21. Hou, X. L.; Li, Y. G.; Cao, S. J.; Zhang, Z. W.; Wu, Y. N. Analysis of Para Red and 361 Sudan Dyes in Egg Yolk by UPLC-MS-MS. Chromatographia 2010, 71 (1-2), 135-138.

362 22. Herrero, M.; Garcia-Canas, V.; Simo, C.; Cifuentes, A. Recent advances in the 363 application of capillary electromigration methods for food analysis and Foodomics. 364 Electrophoresis 2010, 31 (1), 205-228.

365 23. Simo, C.; Garcia-Canas, V.; Cifuentes, A. Chiral CE-MS. Electrophoresis 2010, 31 366 (9), 1442-1456.

367 24. Boyce, M. C. Determination of additives and organic contaminants in food by CE 368 and CEC. Electrophoresis 2007, 28 (22), 4046-4062.

369 25. Mejia, E.; Ding, Y. S.; Mora, M. F.; Garcia, C. D. Determination of banned sudan 370 dyes in chili powder by capillary electrophoresis. Food Chem. 2007, 102 (4), 1027$371 \quad 1033$. 
372 26. Liu, S. F.; Zhang, X.; Lin, X. C.; Wu, X. P.; Fu, F. F.; Xie, Z. H. Development of a

373 new method for analysis of Sudan dyes by pressurized CEC with amperometric 374 detection. Electrophoresis 2007, 28 (11), 1696-1703.

375 27. Niessen, W. M. A.; Tjaden, U. R.; Vandergreef, J. Capillary Electrophoresis Mass376 Spectrometry. J. Chromatogr. A 1993, 636 (1), 3-19.

377 28. Rundlett, K. L.; Armstrong, D. W. Mechanism of signal suppression by an ionic 378 surfactants in capillary electrophoresis electrospray ionization mass spectrometry. Anal. 379 Chem. 1996, 68 (19), 3493-3497.

380 29. Muijselaar, P. G.; Otsuka, K.; Terabe, S. On-line coupling of partial-filling micellar 381 electrokinetic chromatography with mass spectrometry. J. Chromatogr. A 1998, 802 (1), $382 \quad 3-15$.

383 
FIGURE CAPTIONS

385

386 Figure 1. Structures of the four Sudan dyes analyzed in this work.

387

388 Figure 2. Effect of SDS and ammonium bicarbonate concentration on MEKC 389 separation of Sudan I to IV (10 $\mu \mathrm{g} \mathrm{mL}^{-1}$ each) by partial filling with $25 \%$ buffer MEKC 390 and $75 \%$ CZE buffer. (A) MEKC buffer composed of $30 \mathrm{mM} \mathrm{NH} \mathrm{NCO}_{3}$ and $30 \% \mathrm{v} / \mathrm{v}$ 391 ACN with $15 \mathrm{mM}, 25 \mathrm{mM}$ and $50 \mathrm{mM}$ SDS and CZE buffer composed of $30 \mathrm{mM}$ $\mathrm{NH}_{4} \mathrm{HCO}_{3}$ and $30 \% \mathrm{v} / \mathrm{v}$ ACN (B) MEKC buffer composed of 20, 30 and $40 \mathrm{mM}$ $\mathrm{NH}_{4} \mathrm{HCO}_{3}, 25 \mathrm{mM}$ SDS and $30 \% \mathrm{v} / \mathrm{v} \mathrm{ACN}$ and the respective CZE buffer contained

394 the same concentration of $\mathrm{NH}_{4} \mathrm{HCO}_{3}$ and $30 \%$ v/v ACN. Other conditions: run voltage $39530 \mathrm{kV}$, detection wavelength $214 \mathrm{~nm}$; sample injected at 0.5 psi for $5 \mathrm{~s}$; capillary with 396 $50 \mu \mathrm{m}$ i.d., $60 \mathrm{~cm}$ of total length and $50 \mathrm{~cm}$ of detection length.

398 Figure 3. Electropherograms of a standard mixture of Sudan I-IV (20 $\mu \mathrm{g} \mathrm{mL} \mathrm{m}^{-1}$ each) 399 partially filling a percentage of the capillary with the MEKC buffer of (A) $100 \%$, (B) 75 $400 \%$; (C) $50 \%$, and (D) $25 \%$. MEKC buffer: $30 \mathrm{mM} \mathrm{NH} \mathrm{HCO}_{3}, 25 \mathrm{mM}$ SDS and $30 \%$ 401 (v/v) ACN; CZE buffer: $30 \mathrm{mM} \mathrm{NH}_{4} \mathrm{HCO}_{3}$ and $30 \%(\mathrm{v} / \mathrm{v}) \mathrm{ACN}$. Other conditions as in 402 Figure 2.

403

404 Figure 4. Effect of acetonitrile percentage on the separation of a standard mixture of 405 Sudan I to IV (10 $\mu \mathrm{g} \mathrm{mL}^{-1}$ each) plus the internal standard (I.S., $10 \mu \mathrm{g} \mathrm{mL} \mathrm{m}^{-1}$ of 406 flumequine) by partial filling $25 \%$ of the capillary with MEKC buffer and $75 \%$ with 407 CZE buffer. (A) MEKC solution contained $30 \mathrm{mM} \mathrm{NH} \mathrm{HCO}_{3}, 25 \mathrm{mM}$ SDS and $30 \%$ 408 (v/v) ACN; CZE buffer composed of $30 \mathrm{mM} \mathrm{NH}_{4} \mathrm{HCO}_{3}$ and $32.5 \%$ (v/v) ACN; (B) 
409 MEKC solution contained $40 \mathrm{mM} \mathrm{NH}_{4} \mathrm{HCO}_{3}, 25 \mathrm{mM}$ SDS and $32.5 \%$ (v/v) ACN; CZE

410 buffer composed of $40 \mathrm{mM} \mathrm{NH} \mathrm{NHCO}_{3}$ and $32.5 \%(\mathrm{v} / \mathrm{v}) \mathrm{ACN}$. Other conditions as in

411 Figure 2.

412

413 Figure 5. Electropherograms of chilli tomato sauce (A) and the same chilli tomato

414 sauce spiked with $2.5 \mu \mathrm{g} \mathrm{mL}^{-1}$ of Sudan I and II and $5 \mu \mathrm{g} \mathrm{mL} \mathrm{m}^{-1}$ of Sudan III and IV (B).

415 Other conditions as in Figure 4B.

416

417 Figure 6. Partial filling MEKC-MS extracted ion electropherograms (EIE) of a standard 418 mixture containing $5 \mu \mathrm{g} / \mathrm{mL}$ of each Sudan dye. Conditions: uncoated fused-silica 419 capillary, $50 \mu \mathrm{m}$ ID $\times 80 \mathrm{~cm}$ total length; CZE buffer composed of $40 \mathrm{mM}$ ammonium 420 bicarbonate and $32.5 \%$ ACN (v/v); the capillary was partially filled (25\%) with a 421 MEKC solution composed of $40 \mathrm{mM}$ ammonium bicarbonate, $25 \mathrm{mM}$ SDS and $32.5 \%$ $422 \mathrm{ACN}(\mathrm{v} / \mathrm{v})$; sample injected at 0.5 psi for $6 \mathrm{~s}$; applied voltage, $25 \mathrm{kV}$; temperature, 25 $423{ }^{\circ} \mathrm{C}$. ESI conditions: positive ion mode; spray voltage, $4.5 \mathrm{kV}$; sheath liquid, 424 isopropanol/water $(50 / 50 \mathrm{v} / \mathrm{v})$ with $0.1 \%$ formic acid at $4 \mu \mathrm{L} / \mathrm{min}$; drying gas flow, 4 $425 \mathrm{~L} / \mathrm{min}$; drying temperature, $200^{\circ} \mathrm{C}$; nebulizer pressure, $4 \mathrm{psi}$. 
Table 1. Repeatability and limit of detection (LOD) obtained for the four Sudan dyes using the partial filling-MEKC method.

\begin{tabular}{|c|c|c|c|c|}
\hline \multirow[b]{2}{*}{ Analyte } & \multicolumn{3}{|c|}{ Repeatability (\%RSD, $n=10$ ) } & \multirow{2}{*}{$\begin{array}{c}\text { LOD } \\
\left(\mu \mathrm{g} \mathrm{mL}^{-1}\right)\end{array}$} \\
\hline & Migration Time & Corrected Peak Area $^{1)}$ & Relative Peak Area $^{2)}$ & \\
\hline Sudan I & 1.3 & 24.5 & 8.8 & 1.28 \\
\hline Sudan II & 1.5 & 25.5 & 7.5 & 1.53 \\
\hline Sudan III & 2.2 & 23.6 & 9.6 & 2.19 \\
\hline Sudan IV & 3.1 & 12.5 & 25.4 & 3.07 \\
\hline
\end{tabular}

${ }^{1)}$ Corrected peak area calculated as (peak area)/(migration time)

${ }^{2)}$ Relative peak area calculated as (analyte corrected peak area)/(internal standard corrected peak area). Flumequine was used as internal standard. 
Table 2. Intra-day and inter-day precision and limit of detection obtained.

\begin{tabular}{|c|c|c|c|c|c|}
\hline \multirow[b]{2}{*}{ Analyte } & \multicolumn{2}{|c|}{$\begin{array}{c}\text { Intra-day precision } \\
(\% \mathrm{RSD}, \mathbf{n}=10)\end{array}$} & \multicolumn{2}{|c|}{ 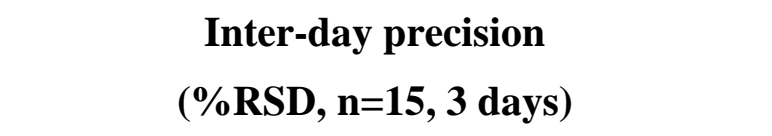 } & \multirow[t]{2}{*}{$\begin{array}{c}\text { LOD } \\
\left(\mu \mathrm{g} \mathrm{m} \mathbf{L}^{-1}\right)\end{array}$} \\
\hline & Migration Time & Relative Peak Area $^{1)}$ & Migration Time & Relative Peak Area $^{1)}$ & \\
\hline Sudan I & 2.3 & 3.2 & 2.3 & 4.1 & 0.57 \\
\hline Sudan II & 2.5 & 5.9 & 2.5 & 5.8 & 0.63 \\
\hline Sudan III & 2.8 & 5.2 & 2.9 & 6.9 & 0.66 \\
\hline Sudan IV & 3.2 & 8.8 & 3.3 & 9.9 & 0.71 \\
\hline
\end{tabular}

${ }^{1)}$ Relative peak area calculated as (analyte corrected peak area)/(internal standard corrected peak area). Flumequine was used as internal standard. 
Table 3. Results of calibration of peak area ratio versus concentration of Sudan I-IV (concentration interval from 2.5 to $20 \mu \mathrm{g} \mathrm{mL}^{-1}$ ). Flumequine was used as internal standard at $10.0 \mu \mathrm{g} \mathrm{mL}^{-1}$.

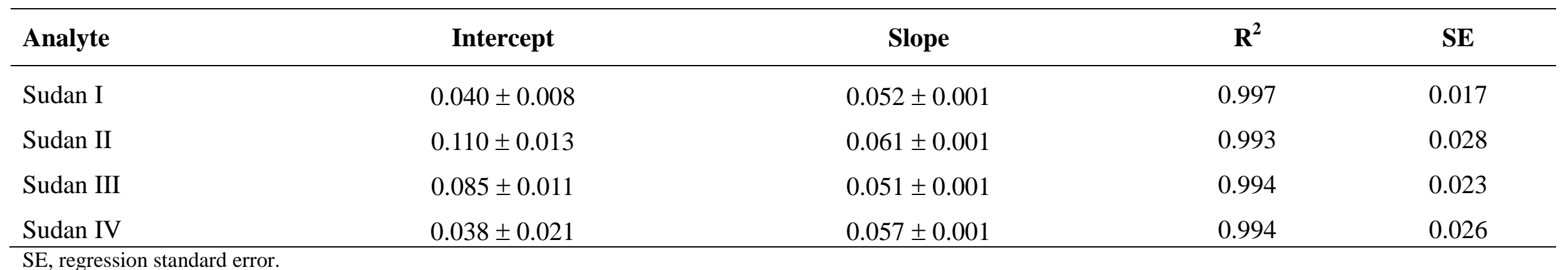

SE, regression standard error. 
Table 4. Recovery values of Sudan I-IV from different chilli tomato sauces. Chilli samples were spiked with $2.5 \mu \mathrm{g} \mathrm{mL}^{-1}$ of Sudan I and II and 5 $\mu \mathrm{g} \mathrm{mL}{ }^{-1}$ of Sudan III and IV.

\begin{tabular}{lccr}
\hline & & \multicolumn{3}{c}{ Recoveries (\%) } & Chilli tomato sauce 3 \\
\cline { 2 - 4 } Analyte & Chilli tomato sauce 1 & Chilli tomato sauce 2 & $95.3 \pm 6.1$ \\
Sudan I & $98.2 \pm 1.0$ & $95.2 \pm 2.5$ & $92.1 \pm 1.2$ \\
Sudan II & $99.0 \pm 2.7$ & $97.2 \pm 1.1$ & $88.4 \pm 4.2$ \\
Sudan III & $90.4 \pm 1.2$ & $92.1 \pm 2.2$ & $85.2 \pm 2.5$ \\
Sudan IV & $85.5 \pm 5.2$ & $90.4 \pm 3.4$ & \\
\hline
\end{tabular}


Figure 1<smiles>Oc1ccc2ccccc2c1/N=N/c1ccccc1</smiles>

\section{Sudan I}<smiles>Cc1ccc(/N=N/c2c(O)ccc3ccccc23)c(C)c1</smiles>

Sudan II

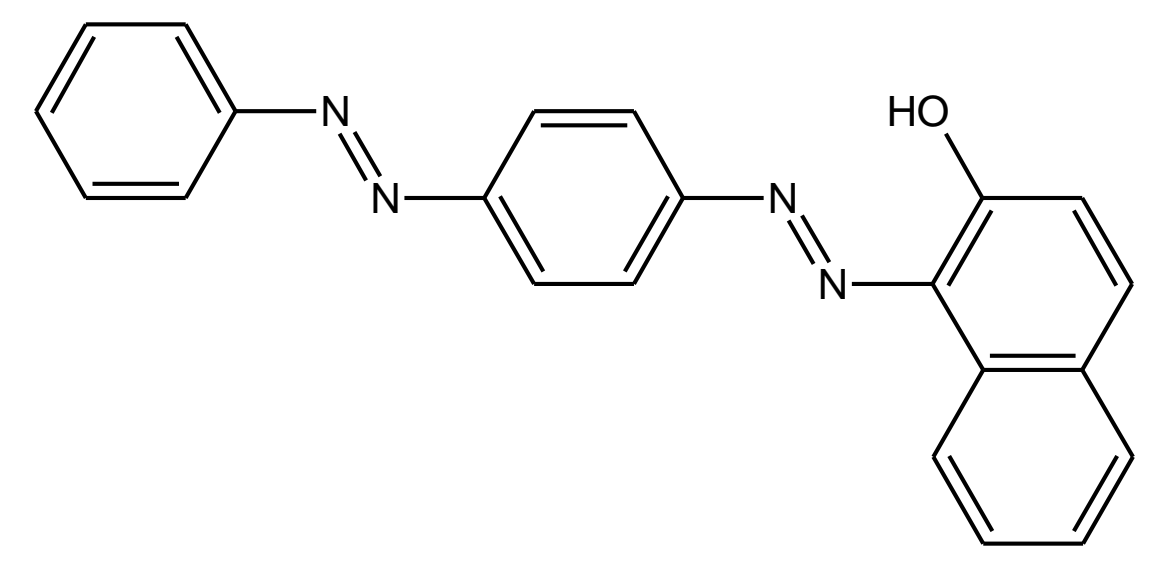

Sudan III

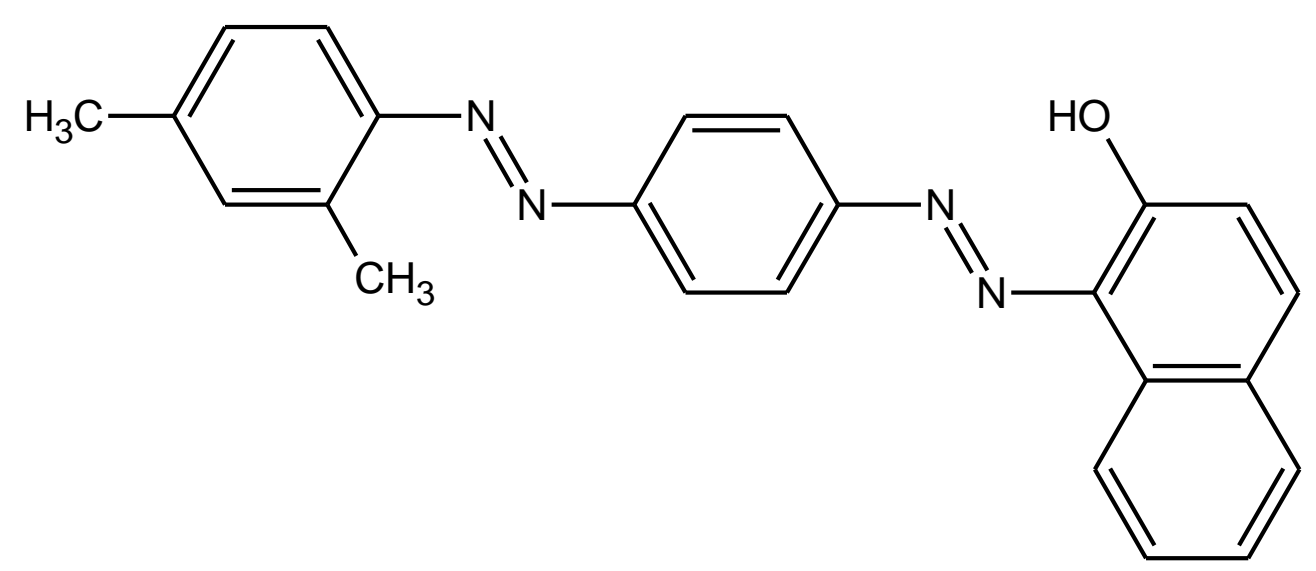

Sudan IV 
Figure 2
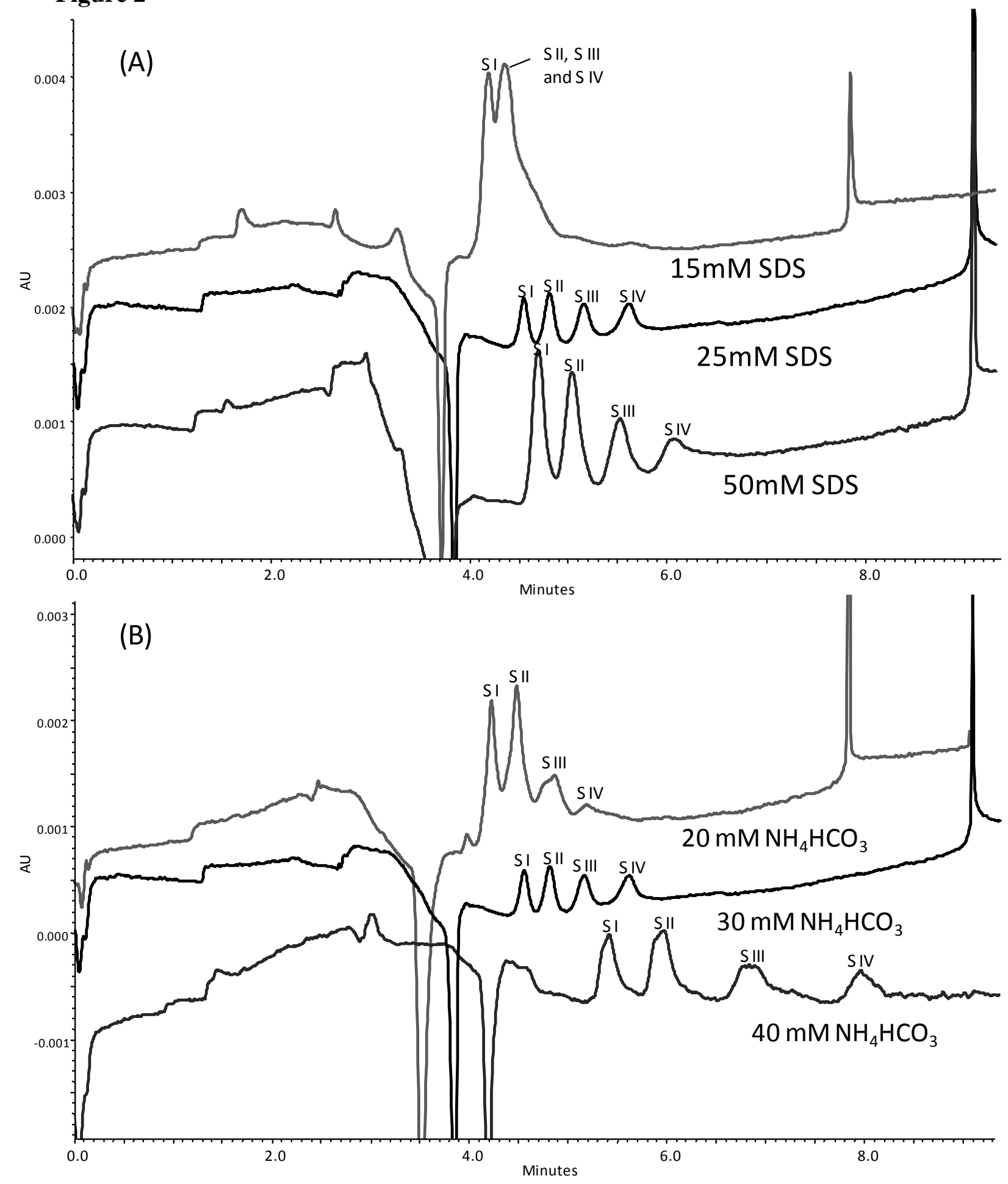


\section{Figure 3}

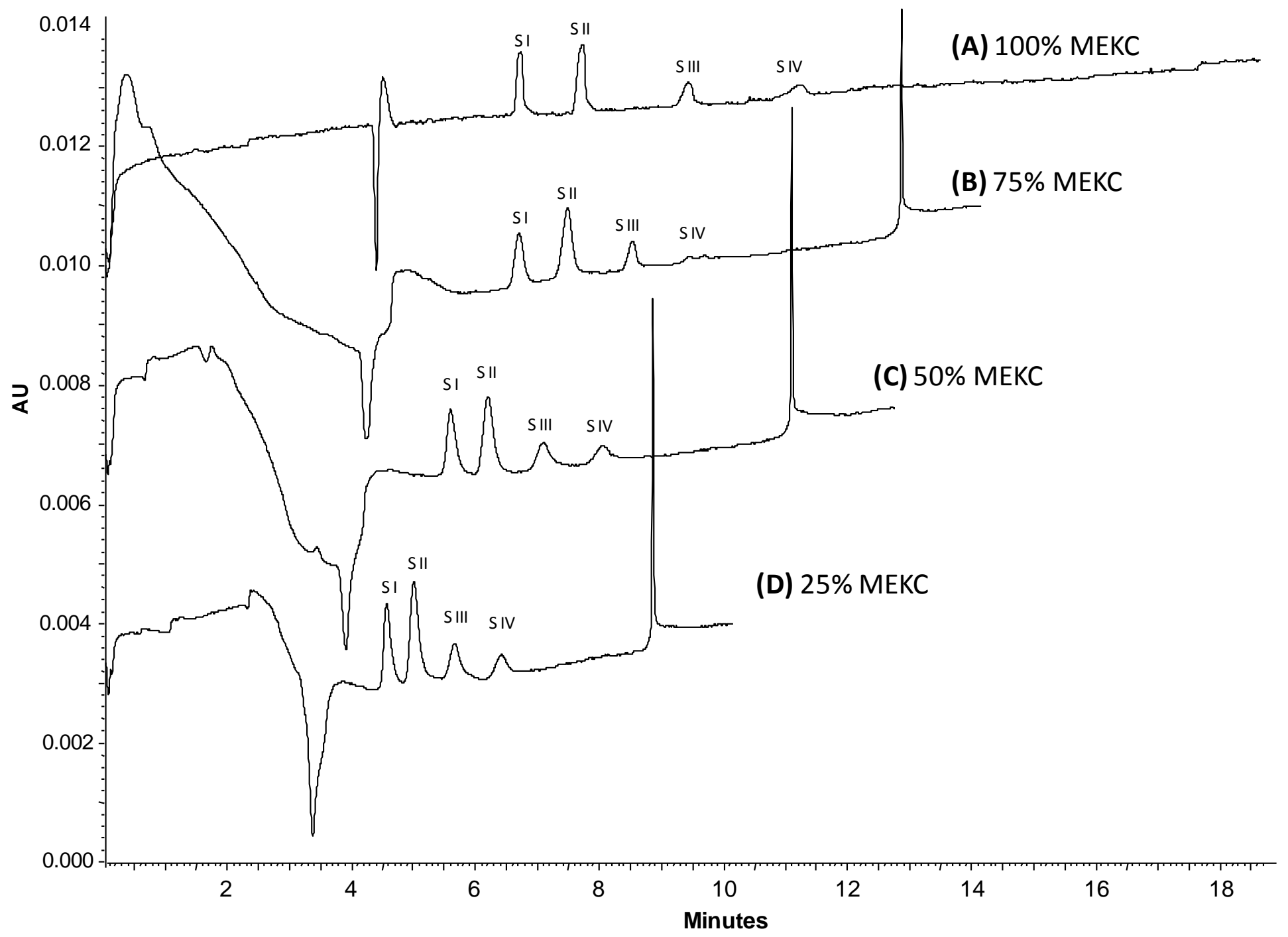




\section{Figure 4}
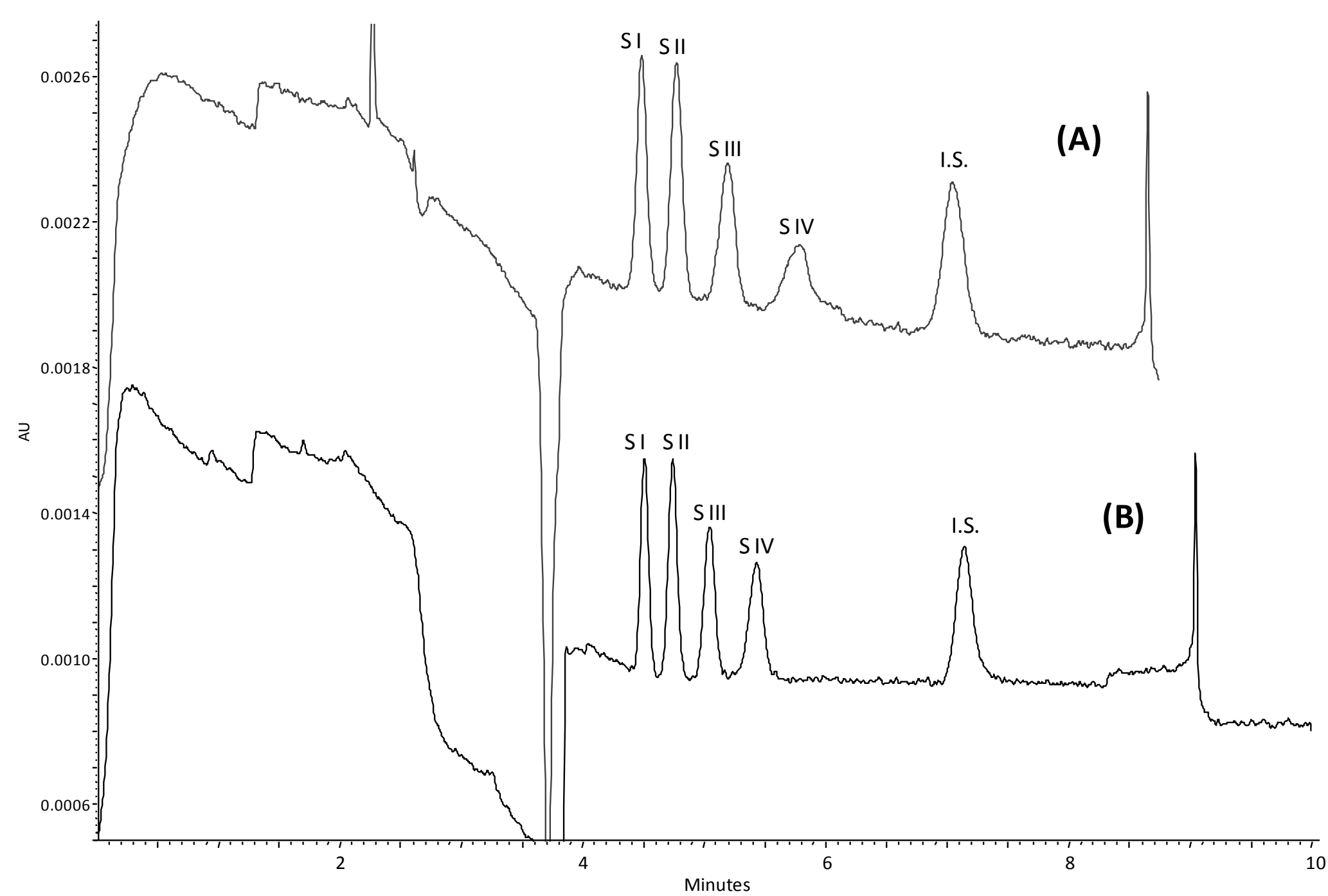
Figure 5.

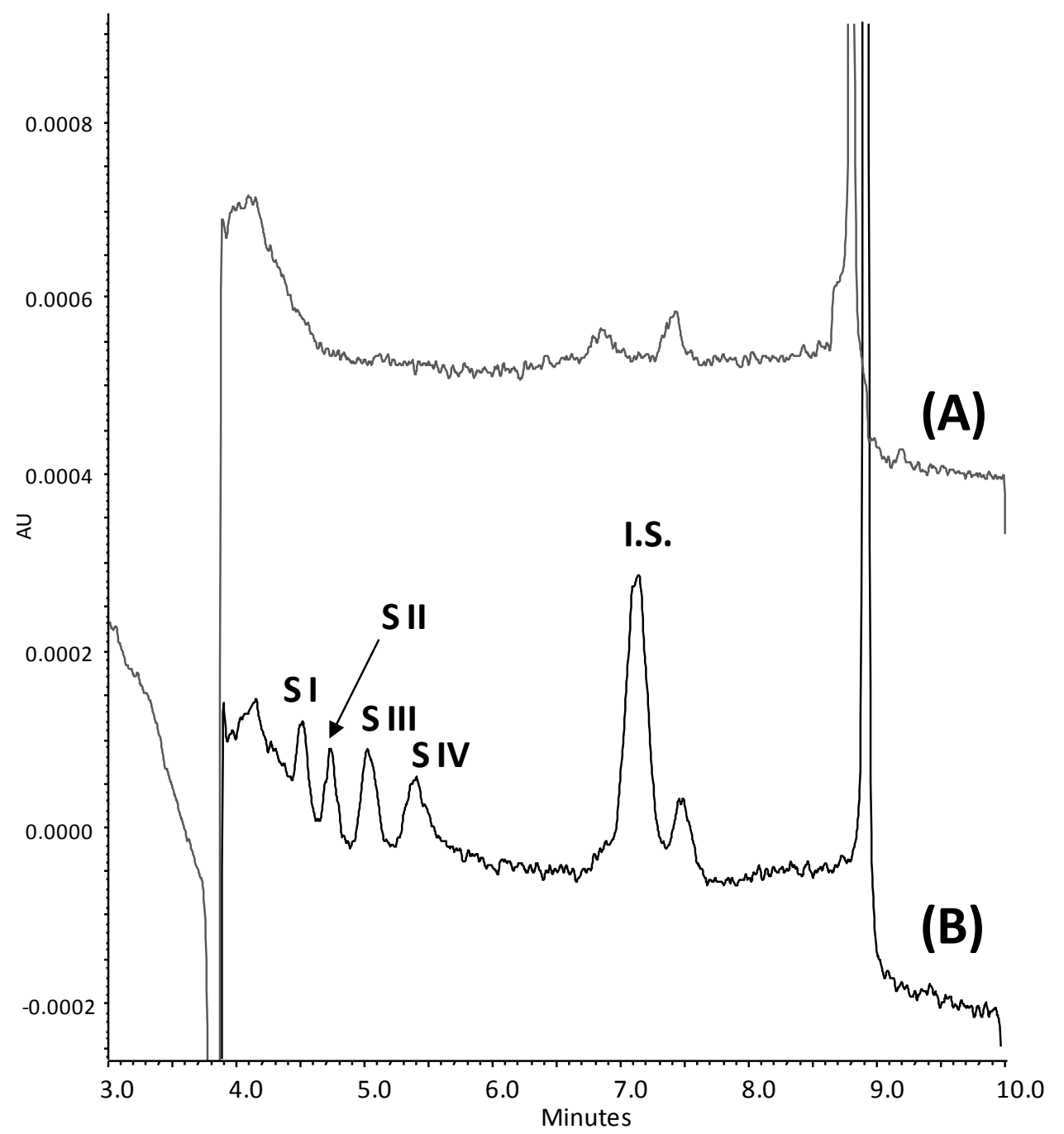


Figure 6.

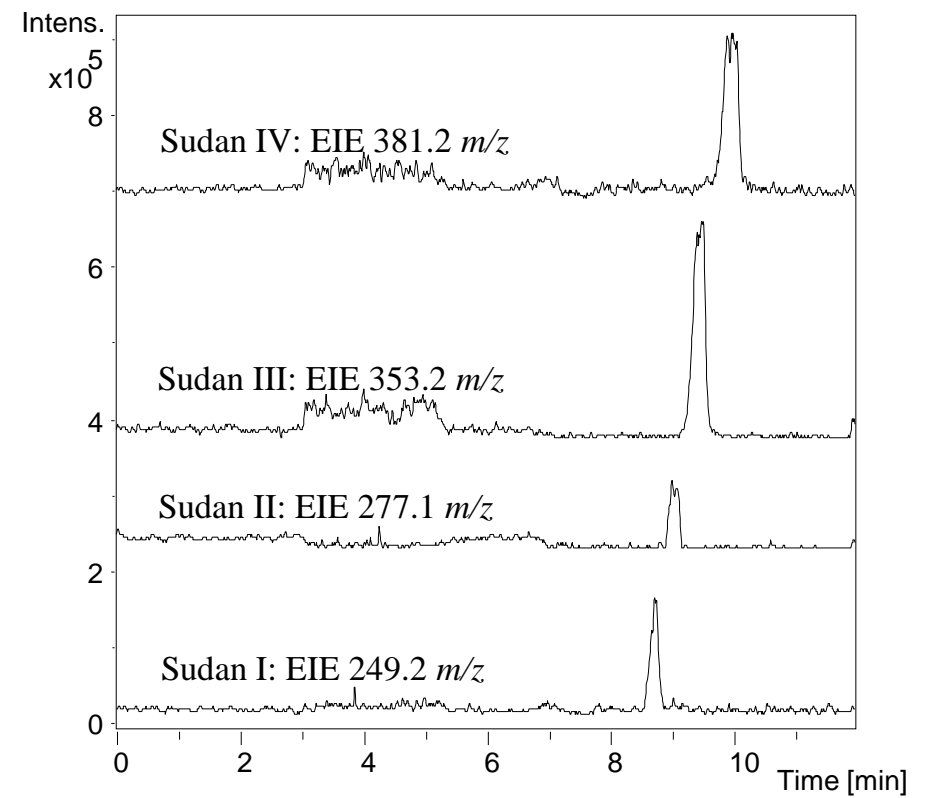

